\title{
Correlations Between Opinions About Mental IIIness and Attitudes Towards Psychological Help Seeking for a Mental Illness Among College Students in Kenya
}

\author{
Nyavanga Eunice Jemalel ${ }^{1,2, *}$, Mourice Barasa Wafula ${ }^{3}$, Chebet Ivy Mmbone M, $^{4}$ \\ ${ }^{1}$ Department of Social and Human Development, Faculty of Social Sciences and Technology, The Technical University of Kenya, Nairobi, \\ Kenya \\ ${ }^{2}$ Malel Bibwob Clinical Psychologists Consultancy Ltd. (MICAP), Nairobi, Kenya \\ ${ }^{3}$ International Planned Parenthood Federation, Africa Region, Nairobi, Kenya \\ ${ }^{4}$ Department of Nursing, Faculty of Health Sciences, the Australian Catholic University, Melbourne, Australia \\ ${ }^{5}$ Nursing Department, Neuroscience Ward, St. Vincent Private Hospital, Melbourne, Australia
}

Email address:

enyavanga@yahoo.com (N. E. Jemalel), barazam@gmail.com (M. B. Wafula), ivymmbone@yahoo.com (C. I. Mmbone)

${ }^{*}$ Corresponding author

\section{To cite this article:}

Nyavanga Eunice Jemalel, Mourice Barasa Wafula, Chebet Ivy Mmbone. Correlations Between Opinions About Mental Illness and Attitudes Towards Psychological Help Seeking for a Mental Illness Among College Students in Kenya. Psychology and Behavioral Sciences.

Vol. 6, No. 4, 2017, pp. 54-58. doi: 10.11648/j.pbs.20170604.12

Received: June 9, 2017; Accepted: June 21, 2017; Published: July 20, 2017

\begin{abstract}
Primary school teacher trainees in Kenya have been identified to have both negative opinions about mental illness and attitudes towards professional psychological help seeking for a mental health problem. This study aims at determining the relationship between opinions about mental illness and attitudes towards professional psychological help seeking for mental illness among college students in Kenya. This study used a self-administered demographic questionnaire, opinions about mental illness and attitudes towards professional psychological help seeking to collect data, among 2777 primary teacher trainees in Kenya. SPSS version 19 was used to analyses data. It was found that there is a positive correlation that was significant at $\mathrm{p}=0.000$ between opinions about mental illness and attitudes towards professional psychological help seeking in this population; this is in line with other studies globally. This study recommended an intervention through psychoeducation of mental illness to improve both opinions about mental illness leading to attitudes towards professional psychological help for a mental illness.
\end{abstract}

Keywords: Correlation, Mental Illness, Opinions, Attitudes, College Students

\section{Introduction}

Research from the developed world indicates that college students do not seek help for a mental illness partly due to negative opinions about mental illness, [1]. Younger adults have been found to have more negative attitudes towards seeking help compared to older adults, [2]. Furthermore, health professions have also been found to hold negative attitudes towards the mentally ill, [3].

There is low research on mental health of the youth and college students in this region; with the common knowledge that these illnesses strike at a prime age of individuals, between 10-24 years of age, [4, 5]. Further more mental illnesses have greater rate of disability adjusted life years (DALYS), identified at 2.5 times more than the developed world, [6]. In addition, Kessler et al, [4] identified that mental illness is common and many begin at childhood and adolescence. They projected lifetime risk to be between 17\%$69 \%$ that is higher than lifetime prevalence of $22-44 \%$. 


\section{Main Body}

\subsection{Importance of Correlation of Opinions about Mental Illness and Attitudes Towards Professional Psychological Help Seeking for a Mental Illness}

Mental illness is known to strike individuals in their youth $[2,4]$, and most of college students are in their youthful age in Kenya. These youth do not seek help, [7] yet some of the barriers to attitudes to professional psychological help seeking among young people among 22, identified papers, identified knowledge about mental illnesses services among others, [7]. Correlation between opinions between opinions of mental illness and attitudes towards professional psychological help seeking would go a long way to identify strategies to help these population seek help through changing opinions that may help in help seeking of the youth.

\subsection{Justifications and Significance of the Study}

Gureje et al, [8] in a Nigerian Community study of knowledge of mental illness and attitudes to mental illness indicated that this community had poor knowledge of mental illness, negative attitudes to mental illness that is fueled by fear and causation, and that individuals with mental illness are to blame for illness.

Several studies done globally have pointed out that one of the main barriers to seeking help for mental illness is negative opinions about mental illness. [10, 11]. Young people have been found to delay seeking for professional help in Uganda, Liberia and Nepal with Uganda identifying community related barriers among others that relate to beliefs and myths of associated with mental disorders [11]. This is similar with what was found in South Eastern Nigeria, where patients living with mental disorders sought traditional healers first, [12]. In addition, a recent study in Kenyan primary school going children has identified them to experience stigmatizing attitudes towards mental illness, which has been a barrier to professional help seeking [13] This may be partly due to negative opinions about mental illness; however no studies have been identified between help seeking and attitudes towards mental illness in this region, This study aims to determine the relationship between attitudes towards mental illness and attitudes towards professional psychological help seeking for a mental illness among college students in Kenya.

Nyavanga \& Barasa, [14, 15] 2016, found out that both opinions (attitudes) about mental illness and attitudes towards professional psychological help seeking for a mental illness among teacher trainees are negative among college students in Kenya. The relationship (correlation) between these two variables is not known among the youth and college students in this region. This study therefore aims to find out the relationship (correlation) between opinions about mental illness and attitudes towards professional help seeking for a mental illness in order to guide this country in developing programs that aim at preventing mental illness and promoting mental health of both the youth and college students.

\section{Methods}

\subsection{Settings and Study Population}

This study is part of longitudinal quasi-experimental (intervention) study; The effects of psychoeducation on attitudes toward mental health seeking behavior among students of primary school teachers training in colleges in Kenya." Four out of twenty (20), teacher-training colleges were conveniently sampled because it was established that trainees were recruited on a quarter system nationally. Among these four training colleges, an estimate of 3, 400 out of 17,000 participants were expected to take part, but only 2925 trainees were present during the time of the study.

All present student trainees who consented for the study were recruited and these researchers assumed that these participants would understand language in both the assessment tools and would be honest and accurate in their responses. Out of the 2925 set of presented questionnaires, only 2777 were returned fully filled, a response rate of $94.32 \%$.

\subsection{Teacher Training in Kenya}

Kenya has twenty (20) public teacher training colleges that enroll approximately 8,500 students yearly who train for two years before they complete course and get a P1 teaching certificate. This then means that there are about 17,000 trainees at each particular time, who have completed Kenya Secondary Certificate of Education (KSCE), with a minimum of a grade C. It was learned that this students are also recruited in a quota system covering the all country and are normally between the ages of 18 to 35 years of age depending on when they completed Secondary education. These trainees at the completion of their certificate course are employed by the Teachers Service Commission or private sector to teach in primary schools depending on availability of vacancies.

\subsection{Procedure and Instrumentation}

A demographic questionnaire asking for age, gender, year of study, marital status and whether taught before coming to college was presented including Opinions about Mental Illness (OMI), by Cohen and Struening, 1970 [16], and Attitudes towards Professional Psychological Help Seeking Scale Short Form (ATPPHS-SF) by Fisher and Turner 1970, [17] to the participants. The OMI, consists of 51 item made up of five opinion variables of Authoritarianism (OMIA), Benevolence (OMIB), Social Restrictiveness (OMIS), Mental Health Hygiene (OMIM), and Interpersonal Etiology, (OMII). The ATPPHS consist of 29 likert scale items, which were designed to assess general attitudes towards seeking professional psychological help for a mental health problem. This study adapted Salim's, [18] minor changers by substituting terms psychiatrists and psychiatric with counselors and psychologists respectively and loaded on four 
main attitude variables of recognition, stigma, openness and confidence.

This data collecting tools were presented to the participants while sited in their normal classrooms with the assistants of trained research assistants after explaining to them the plan, purpose, procedure and implication of the study. They were also told that taking part in the study was voluntary and those who did not want to take part in the study, would withdraw at anytime with no penalty.

The data was collected on paper and captured into SPSS for analysis, which was done using SPSS V23. The analysis included use of Pearson's Correlation Coefficient of the overall correlation between the ATPHS and opinions about mental illness and then a comparison of changes at the different stages of the trials.

\subsection{Ethical Considerations}

The Kenyatta National Hospital and University of Nairobi Ethical Committee approved this study. The ministry of Education gave permission, and the same was also provided by the college administration, after informed consent.

\section{Results, Discussion, Conclusion and Recommendation}

\subsection{Results}

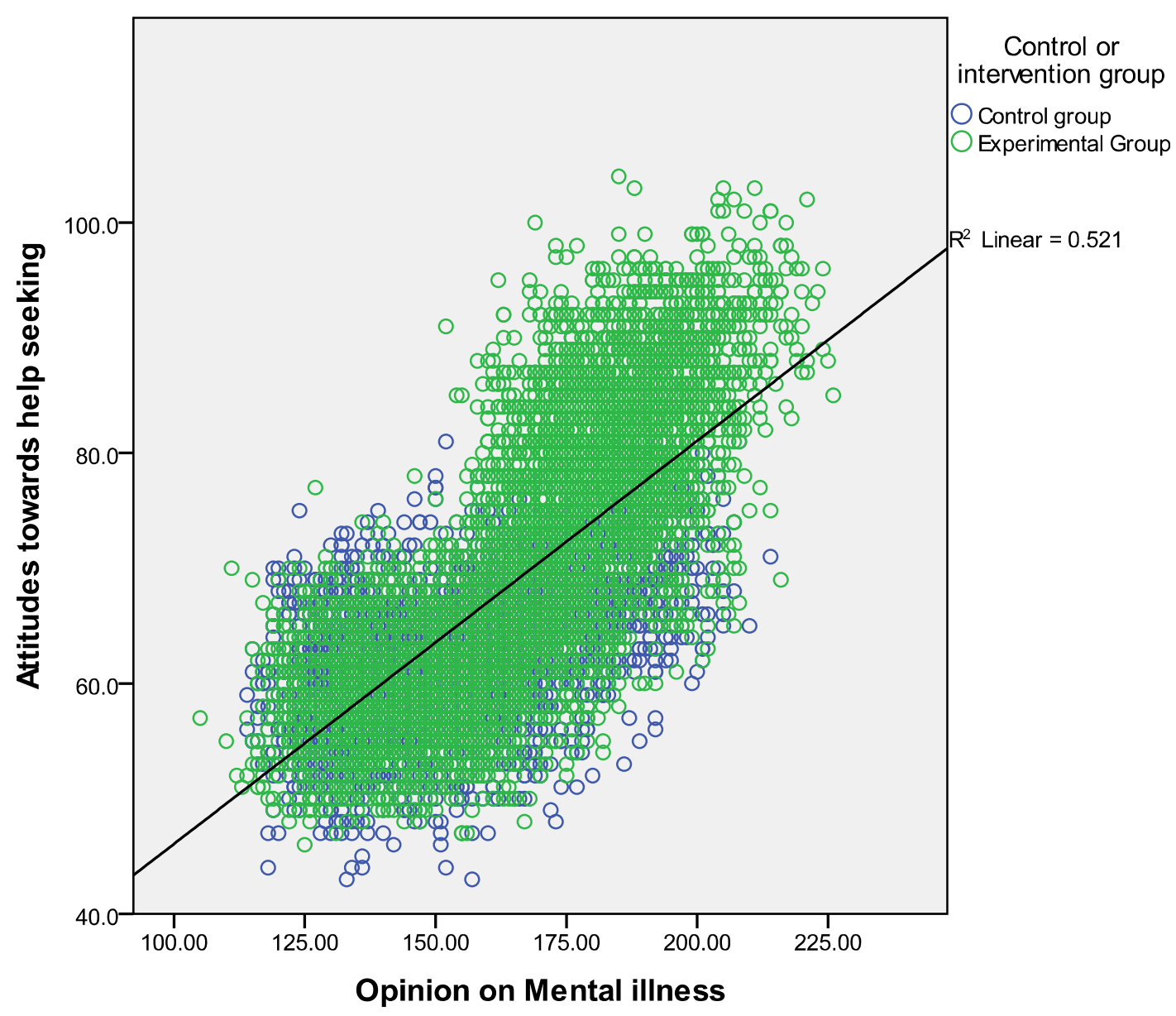

Figure 1. Scatter plot diagram indicating the linear regression between OMI and ATPHHS.

Summative mean scores of OMI and ATPPHS, were plotted, figure 1 (above). Opinions about Mental illness and Attitudes towards Professional Psychological Help seeking were strongly correlated $(\mathrm{r}=0.812, \quad \mathrm{p}$-value $=0.00)$. A goodness of fit between the Attitudes and Opinions $\left(\mathrm{R}^{2}\right.$ $=0.521$ ) seen in Figure 1 was observed. This result implied that the Opinions about Mental illness could only explain $52.1 \%$ of the outcomes in the attitudes towards professional psychological help seeking. This means that Opinions about Mental Illness is not the only factor responsible for the outcomes in the attitudes towards professional psychological help seeking but other factors have also contributed to the outcomes in these attitudes.

\subsection{Discussion}

A return rate of $94.94 \%$ was recorded. This is in line with other studies with other studies done in Kenya among college students, two studies by Ndetie et al, [19, 20] which registered $100 \%$ return rate.

The Relationship between Opinions about Counseling and 
Attitudes towards Professional Psychological Help Seeking among the Experimental and Control Groups

There was a positive significant correlation between Opinions about Mental Illness and Attitudes towards Professional Psychological Help Seeking and a goodness fit. This is consistent with other findings, [21, 22 23]. In a study of stigma and help seeking, Tucker et al [21] reported that stigmatizing opinions of mental illness predicted poor help seeking attitudes for a mental disorder among individuals. Similarly in a metaanalysis, Hadlaczky et al [22] \& Clement et al [23] pointed out that improving knowledge of mental illness decreased their negative opinions about mental illness; in addition leading to an improvement of attitudes towards help seeking.

This result suggest that although Opinions about counseling influences the Attitudes towards Professional Psychological Help seeking by $52.1 \%$, other factors as well contribute to the impact of attitudes towards professional psychological help seeking behavior in both groups. Studies have found out that there is need to provide mental health education to college students in order to improve attitudes towards professional psychological help seeking on mental health issues, [24, 25].

Stigma and discriminating attitudes against individuals with mental illness are major global challenges in the treatment of mental illness because they lead to negative attitudes to seeking professional psychological help, [26, 27]. Studies have found out that stigmatizing opinions about mental illness highly contribute to negative attitudes towards help seeking among various populations, [23].. This then calls for psychologists and other to reduce stigmatizing opinions (attitudes) towards mental illness in order to improve attitudes to help seeking among the mentally ill.

Young people need to understand what mental illness is, the causes, the consequences, and the treatment options available, so they can be able to change their attitudes towards seeking professional help for the same [23, 26, 27]. The "Time To Change" program introduced in England among the British people between 2009-2012 among adults only saw a minimal improvement in the intended behavior [28]. This then calls for improved programs to change opinions about mental illness that may eventually change attitudes towards seeking professional psychological help for the same.

\subsection{Conclusion}

There is a strong relationship between Opinions about Mental Illness and Attitudes towards Professional Psychological Help Seeking among these participants. This means that with improved opinions there are improved attitudes towards help seeking.

\subsection{Recommendations}

This study recommends that the youth and college students specifically should be given education on mental illness so that they can be able to improve their opinions about mental illness, hence attitudes towards professional psychological help seeking for a mental illness. This study also recommends more research on other factors that contribute to attitudes towards professional psychological help seeking for a mental illness among they youth and college students. It also recommends that the government of Kenya through the Ministry of Education and the Teachers Service Commission, should review, update and develop policies that address mental health issues and seeking professional help for teacher trainees, advocate for increased funding for mental health advocacy and programs, and provide school psychologists that would help teachers who are likely to be mentally ill in schools.

\section{Acknowledgements}

This study was not funded, but we would like to acknowledge the African Mental Health Foundation, (AMHF) and the Bibwob-Malel Clinical Psychologist Consultants Ltd., (MICAP), for the generous contributions in terms of accessing the Internet and the journals used in this study. We also would like to acknowledge the heads of institutions for arrangement participants and allowing us do this study in between their very busy schedule,

\section{References}

[1] Eisenberg, D., Downs, M. F., Golberstein, E., \& Zivin, K. (2009). Stigma and help seeking for mental health among college students. Medical Care Research and Review, 66 (5), 522-541.

[2] Mackenzie, C. S., Gekoski, W. L., \& Knox, V. J. (2006). Age, gender, and the underutilization of mental health services: the influence of help-seeking attitudes. Aging and Mental Health, 10 (6), 574-582. |http://dx.doi.org/10.1080/13607860600641200

[3] Bennett, J. and Stennett, R. (2015), Attitudes towards mental illness of nursing students in a Baccalaureate programme in Jamaica: a questionnaire survey. Journal of Psychiatric and Mental Health Nursing, 22: 599-605. doi: 10.1111/jpm.12234.

[4] Christie, K. A., Burke, J. D., Regier, D. A., Rae, D. S., Boyd, J. H., \& Locke, B. Z. (1988). Epidemiologic evidence for early onset of mental disorders and higher risk of drug abuse in young adults. Am J Psychiatry, 145 (8), 971-975.

[5] Kessler RC, Berglund P, Demler O, Jin R, Merikangas KR, Walters EE. Lifetime Prevalence and Age-of-Onset Distributions of DSM-IV Disorders in the National Comorbidity Survey Replication. Arch Gen Psychiatry. 2005; 62 (6): 593-602. doi: 10.1001/archpsyc.62.6.593.

[6] Whiteford, H. A., Degenhardt, L., Rehm, J., Baxter, A. J., Ferrari, A. J., Erskine, H. E.,... \& Burstein, R. (2013). Global burden of disease attributable to mental and substance use disorders: findings from the Global Burden of Disease Study 2010. The Lancet, 382 (9904), 1575-1586.

[7] Gureje, O., Victor O. Lasebikan, Olusola EphraimOluwanuga, Benjamin O. Olley, Lola Kola. Community study of knowledge of and attitude to mental illness in Nigeria. The British Journal of Psychiatry Apr 2005, 186 (5) 436-441; DOI: 10.1192/bjp.186.5.436. 
[8] Gulliver, A., Griffiths, K. M. \& Christensen, H. Perceived barriers and facilitators to mental health help-seeking in young people: a systematic review. BMC Psyciatriy, 2010; 10: 113. DOI: $10.1186 / 1471-244 X-10-113$.

[9] Komiya, N., Good, G. E., \& Sherrod, N. B. (2000). Emotional openness as a predictor of college students' attitudes toward seeking psychological help. Journal of counseling psychology, $47(1), 138$.

[10] Eisenberg, D., Golberstein, E., \& Gollust, S. E. (2007). Helpseeking and access to mental health care in a university student population. Medical care, 45 (7), 594-601.

[11] Kisa, R., Baingana, F., Kajungu, R., Mangen, P. O., Angdembe, M., Gwaikolo, W., \& Cooper, J. (2016). Pathways and access to mental health care services by persons living with severe mental disorders and epilepsy in Uganda, Liberia and Nepal: a qualitative study. BMC psychiatry, 16 (1), 305.

[12] Odinka, P. C., Oche, M., Ndukuba, A. C., Muomah, R. C., Osika, M. U., Bakare, M. O.,... \& Uwakwe, R. (2014). The socio-demographic characteristics and patterns of helpseeking among patients with schizophrenia in south-east Nigeria. Journal of health care for the poor and underserved, 25 (1), 180-191.

[13] Ndetei, D. M., Mutiso, V., Maraj, A., Anderson, K. K., Musyimi, C., \& McKenzie, K. (2016). Stigmatizing attitudes toward mental illness among primary school children in Kenya. Social psychiatry and psychiatric epidemiology, 51 (1), 73-80.

[14] Eunice Jemalel Nyavanga, Maurice Barasa. Opinions About Mental Illnes Among Primary School Teacher Trainees in Kenya. Psychology and Behavioral Sciences. Vol. 5, No. 3, 2016, pp. 62-68. doi: 10.11648/j.pbs.20160503.11.

[15] Eunice Jemalel Nyavanga, Mourice Barasa. Attitudes Towards Professional Psychological Help Seeking Among Young Adults in Kenya: Case Study of Public Teacher Training Colleges. Psychology and Behavioral Sciences. Vol. 5, No. 3, 2016, pp. 69-76. doi: 10.11648/j.pbs.20160503.12.

[16] Cohen J. \& Struening E. L. Opinions about mental illness in the personnel of tow large mental hospitals. Journal of Abnormal Social Psychology, 1962; 64: 339-360. http://dx.doi.org/10.1037/h0045526.

[17] Fischer, E. H., \& Turner, J. L. (1970). Orientations to seeking professional help: Development and Research utility of an attitude scale. Journal of Consulting and Clinical Psychology, $35,79-90$.

[18] Suradi Salim. (2010) Psychological Help seeking Attitudes among Malaysian college and University Students. Procedia
Social and Behavioural Sciences; 5: 426-430. Doi: 10.1016/j.sbspro.2010.07.117.

[19] Ndetei, D. M., Khasakhala, L., Nyabola, L., Ongecha-Owuor, F., Seedat, S., Mutiso, V.,... \& Odhiambo, G. (2008). The prevalence of anxiety and depression symptoms and syndromes in Kenyan children and adolescents. Journal of child and adolescent mental health, 20 (1), 33-51.

[20] Ndetei, D. M., Khasakhala, L. I., Mutiso, V., Ongecha-Owuor, F. A., \& Kokonya, D. A. (2009). Psychosocial and health aspects of drug use by students in public secondary schools in Nairobi, Kenya. Substance abuse, 30 (1), 61-68.

[21] Tucker, J. R., Hammer, J. H., Vogel, D. L., Bitman, R. L., Wade, N. G., \& Maier, E. J. (2013). Disentangling self-stigma: Are mental illness and help-seeking self-stigmas different?. Journal of Counseling Psychology, 60 (4), 520.

[22] Hadlaczky, G., Hökby, S., Mkrtchian, A., Carli, V., \& Wasserman, D. (2014). Mental Health First Aid is an effective public health intervention for improving knowledge, attitudes, and behaviour: A meta-analysis. International Review of Psychiatry, 26 (4), 467-475.

[23] Clement, S., Schauman, O., Graham, T., Maggioni, F., EvansLacko, S., Bezborodovs, N.,... \& Thornicroft, G. (2015). What is the impact of mental health-related stigma on help-seeking? A systematic review of quantitative and qualitative studies. Psychological medicine, 45 (1), 11-27.

[24] Hom, M. A., Stanley, I. H., \& Joiner, T. E. (2015). Evaluating factors and interventions that influence help-seeking and mental health service utilization among suicidal individuals: a review of the literature. Clinical psychology review, 40, 28-39.

[25] Taylor-Rodgers, E., \& Batterham, P. J. (2014). Evaluation of an online psychoeducation intervention to promote mental health help seeking attitudes and intentions among young adults: randomised controlled trial. Journal of affective disorders, 168, 65-71.

[26] Thornicroft G., Brohan E., Rose D., Sartorius N, \& Leese M. (2009). Global pattern of experienced and anticipated discrimination against people with schizophrenia: a crosssectional survey. Lancet 373: 408-15.

[27] Ucok A, Brohan E, Rose D, Sartorius N, Leese M, Yoon CK, et al. (2012). Anticipated discrimination among people with schizophrenia. Acta Psychiatr Scand 2012; 125: 77-83.

[28] Evans-Lacko, S., Malcolm, E., West, K., Rose, D., London, J., Rüsch, N.,... \& Thornicroft, G. (2013). Influence of Time to Change's social marketing interventions on stigma in England 2009-2011. The British Journal of Psychiatry, 202 (s55), s77s88. 